on Science and Society", the subtitle might better be stated as "An Attempt to Educate Certain Individuals". Perhaps I am reading too much into the book, but it seems that this was a subtle and responsible attempt to do just that. The difficulty is that the individuals at risk, even if they are science students, are not in this matter students of science. So, although it would be a waste of time to emphasize the paraphernalia of science, the conclusions must be scientifically impeccable; and sensationalism, if it is permitted at all, had best come down in favour of the defendant drug rather than against it. This is what happens here; nevertheless, my chief anxiety in reviewing the book in these terms is that I may have unwittingly blown its "cover". Most of the science, in fact, is confined to the glossary, which is excellent. "Efficacy," for example, is simply defined as "effectiveness"; and the definition of "malvaria" begins "Purportedly"--a good beginning for a definition in a volume tiidt contains a contribution by Abraham Hoffer himself. The other, more usual kind of glossary is of course inappropriate for this audience. In fact, the only traces of student humour are to be found in the name of the publishers ("Stash" also means Student Association for the Study of Hallucinogens, the body that sponsored this symposium), a cover that is got up to look rather like something similar from the National Institute of Mental Health, and the dedication in minute type to the Attorney General of the United States and his wife for their efforts to further America's "enlightened drug policies".

The list of contributors is impressive, and the way they make their points doubly so. Solomon Snyder, for example, quotes the $0 \cdot 1-0.2$ per cent "bad trip" and the 20 per cent flashback rates; Joel Fort notes that "The best way for a society to deal with drugs is to civilize itself"; Daniel Freedman: "The TV show in the head" experienced by Indian peyote users is considered a distraction and not the purpose itself; Stanley Krippner, quoting Plato: "New modes of music herald upheavals in the state"; Hoffer giving unorthodox but interesting advice on how to avoid bad trips; Samuel Irwin, and others, emphasizing chromosome damage as a great potential danger in spite of the inconclusiveness of the evidence, but also giving due weight to the "psychosocial dangers" of hallucinogen taking.

The overall temperature is that of a cool scene; the hot hallucinogens like LSD are, in fact, firmly put down. What is still as badly needed as ever, of course, is a controlled comparative trial of the effectiveness of different means of education: I wonder if the bushfire reactions of those hardline professors who stamp about on public platforms are even half as effective as this kind of student soft sell.

C. R. B. JOYCE

\section{Child Development}

The Child in His Family. (The International Yearbook for Child Psychiatry and Allied Disciplines, Vol. 1.) By E. James Anthony and Cyrille Koupernik. Pp. xxxii + 492. (Wiley-Interscience: New York and London, October 1970.) 120s.

THIs collection of papers, prepared for an international congress on child development, includes work from a number of different viewpoints loosely organized around themes: family dynamics, family vulnerability and crisis, chronic family pathology and studies of families in different cultures. It is the first volume in a yearbook series. Contributions from specialists trained in various behavioural science disciplines add to our knowledge of the complex interactions of family life, culture and personal development. They vary in scope from Lidz's broad discussion of "The Family as the Developmental Setting", to specific reviews and studies such as Bowlby and Parkes's "Separation and Loss within the Family". Anthony's study of the impact of serious mental and physical illness in a parent on family life, and Greenberg's discussion of atypical infant development in relation to the behaviour and personality of the mother amplify and document clinical impressions. Studies of child rearing in Indian, Turkish, African, Sudanese and isolated Norwegian mountain families add to our sense of the range of variability of personality development in response to differences of culture and ecology. In various ways they indicate the value of getting beyond the classical psychoanalytic categories in studying the complexities of human development.

LEONARD J. FrIEDMAN

\section{Fibroblastic Disorders}

The Differential Diagnosis of Fibroblastic Disorders. By D. H. MacKenzie. Pp. ix $+167+88$ plates. (Blackwell Scientific: Oxford and Edinburgh, 1970.) 55s.

DR MACKENZIE's monograph on fibroblastic disorders is an expansion of a Hunterian lecture and has both the merits and defects of such communications. The field of interest is arbitrarily restricted, so that histiocytomas and elastofibroma come within the author's fibroblastic spectrum, but not the fibrous proliferation of nerve sheaths, while treatment and prognosis are dealt with in a most cursory manner.

After a brief account of granulation tissue, MacKenzie considers the various types of inflammatory and hyperplastic fibrous conditions, as well as benign and malignant tumours; each section is illustrated by photomicrographs of good quality and a list of references to relevant papers which will be useful for those who seek a sufficiency of information for the various higher examinations that effectively impede the training of consultants. For the practising surgeon MacKenzie's book will be disappointing as there is little about the natural history of the conditions dealt with, nor will the young diagnostic pathologist gain as much assistance as he would expect from a book concerned with differential diagnosis. If a condition has been named one can use the text for confirmation or thumb through the illustrations, hoping to find an example similar to that seen under the microscope. The problem of differential diagnosis of connective tissue proliferation is far wider than is covered here, embracing vascular tissue, smooth muscle, nerve sheath and fat as well as fibrous tissue and histiocytes, while on occasions anaplastic epithelial conditions may cause confusion; it is a difficult and important problem, for both prognosis and treatment are dependent on accurate diagnosis.

The deficiencies of this expensive little monograph are all the more regrettable as MacKenzie has a wide experience of the conditions which he describes; if his material had been arranged in a different manner and very slightly expanded it could have been a valuable contribution to pathological knowledge. A. H. T. Roвb-SмiтH

\section{Brain Forms}

Catalogue of Mammalian Brains. By Kurt Brauer and .Wilfried Schober. Pp. $20+150$ plates. (Fischer: Jena, 1970.) 173 marks.

IN recent years, a concentration of neuroanatomical research on fine structure and function has led to a preoccupation with the relatively few mammalian brains which can be obtained in considerable numbers and with animals which can be maintained in laboratories for experimental purposes. The very wide range of morphological variation in the brains of different mammals has attracted little attention, and one can welcome the publication of this catalogue as doing something to redress the balance between different interests.

It consists of excellent photographs, each accompanied by an explanatory line drawing, showing the brains of about 150 mammalian species distributed over twelve of the eighteen orders for which living representatives exist. The specimens are in the Brain $\mathrm{Re}$ search Institute at Leipzig, but future instalments are promised which will illustrate additional specimens in other institutions. As the present volume is 